BLS 34, No 1 2008. DOI: http://dx.doi.org/10.3765/bls.v34i1.3586

(published by the Berkeley Linguistics Society and the Linguistic Society of America)

\title{
What's New (and What's Given) in the Theory of Focus?
}

\author{
Daniel Büring
}

\section{Introduction}

Central to virtually all versions of focus semantics is the notion of FOCUS SEMANTIC VALUES, FSVs for short (also called FOCUS ALTERNATIVES). Characterized informally, within a given $\mathrm{F}$ (OCUS)-DomAIN $\mathrm{D}$, the meaning of all focused elements can be replaced by type-identical alternatives, which are combined with the ordinary denotations of non-focused constituents in D in the usual way. The result is a set of alternatives to the ordinary denotation of the domain D.

I will use a shorthand notation for FSVs, writing things like (1a-c) to characterize the FSVs of the root domains in $(2 \mathrm{a}-\mathrm{c})$ :

$$
\begin{array}{ll}
\text { a. } & \text { John } R \text { Mary } \\
\text { b. } & x \text { say Mary } \\
\text { c. } & \text { John saw } y
\end{array}
$$

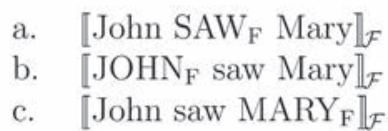

Both of these stand for sets of denotations $d$, where each element in $d$ is of the same type as the ordinary denotation of the sentence John saw Mary, say a set of worlds. Similarly, I'll write things like $(3 \mathrm{a}-\mathrm{c})$ for sets of NP meanings, sets of VP-meanings etc.:

$$
\text { a. } x \text { car }
$$

\footnotetext{
${ }^{0}$ This material was presented in various forms at the Berkelely Linguistics Society, the UCL workshop on Information Structure, and at colloquia at UC Santa Cruz and the Goethe Universität in Frankfurt. Thanks to the audiences there for their comments and suggestions, and to Michael Wagner for discussion of the issues.
} 


\section{Daniel Büring}

\section{b. give $y$ to $z$}

c. $R$ slowly

While FSVs, understood in this specific technical sense, are an essential tool in formulating a theory of focus, they do not by themselves constitute such a theory. We have to specify first, what (pragmatic) conditions the FSV has to meet, and second, when and where to 'retrieve' focus values, that is: where and when to form focus domains.

This paper argues for the following answers to these two questions: In order for a focus domain to be felicitous, its FSV has to include a meaning that is salient in the discourse, but moreover contrastive with the ordinary meaning of the focus domain. In this I follow recent arguments in Wagner (2006), contrary to Rooth (1992) and Schwarzschild (1999). Domains are formed due to principles that aim to maximize anaphoricity, an idea found for focus in Williams (1997) and Sauerland (2005), and in a slightly different way Schwarzschild (1997).

It turns out that the answers to these two questions are subtly intertwined, in a way that I will try to make transparent in this paper. In particular, while Wagner's observations were incompatible with the F-marking system proposed in Schwarzschild (1999), they are unproblematic for the account advocated here. The paper concludes by examining a second case of problematic examples for the Schwarzschild (1999) account, brought up in Kehler (2005), which I suggest can be handled in the present theory as well, but not as easily under the assumptions made in Wagner (2006).

\section{Background}

\subsection{Match and Contrast}

As mentioned above, a theory of focus has to clarify, among other things, which conditions the FSV of a given focus domain has to meet. One possibility often assumed is that the FSV of a given focus domain must contain an element which is salient in the discourse. I will call this condition МAтсH:

(4) Maтch:

For each focus domain D, there is some element $\mathrm{M}$ in the FSV of D which is a salient meaning in the discourse. 
What's New (and What's Given) in the Theory of Focus?

I think Rooth (1992) is a good example of a theory that employs matching in this sense. In that theory, each focus domain restricts a variable, to the effect that its value must be an element of the FSV. ${ }^{1}$ The actual value of the variable must be supplied by the context, which I approximate in (4) by saying that it must be salient. A second example of a matching theory is Schwarzschild (1999), at least in the sense that whenever MATCH is met, so is the Givenness condition in that paper (for the inverse, additional assumptions need to be made which I cannot go into here).

One could assume a stronger condition than MATCH, something like (5):

\section{CONTRAST:}

For each domain D, there is some element M in the FSV of D which is a salient meaning in the discourse and contrasts with the ordinary denotation of $\mathrm{D}$.

The crux, as Rooth (1992) points out, is that the meaning of the word 'contrast' in the definition of CONTRAST in (5) is itself in need of explication; existing attempts in the literature have either fallen short of giving an explicit definition, or provided one which is too narrow to capture all the kinds of cases Rooth intended to be subsumed under his proposal. Moreover, Rooth claims, there is no need for such a stronger notion, since the rather 'weak' notion of MATCHing seems to capture all the cases we need to.

As said above, in section 4 I will side with Wagner (2006) on the latter point, pace Rooth. On the first point, I will offer some tentative remarks on a possible formalization of contrast in section 4.3.

Up until that section I will assume the principle MATCH, in order to facilitate comparison of the present proposal with Rooth (1992) and Schwarzschild (1999).

\subsection{Domain Formation}

The question, when and where to build domains, is not addressed in Rooth (1992), but forms a centerpieces of the proposal in Schwarzschild (1999). In order to demonstrate its relevance, let me first introduce some notation. I will mark focus domains by adjoining an expression $\sim$ ('squiggle'); for example,

\footnotetext{
${ }^{1}$ This is actually only one of two cases discussed in that paper. In the other, which I will ignore in this paper, hopefully without loss of generality, the variable needs to be a subset of the FSV.
} 


\section{Daniel Büring}

in (6), the constituent rooted in $\mathrm{C}$ is a focus domain, $\mathrm{A}$ is the focus of that domain, $\mathrm{B}$ the non-focus of that domain, and $\mathrm{D}$ is outside of the domain altogether:

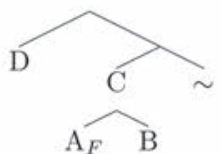

Assuming MATCH in (4) above, (7) must hold for (6) to be felicitous:

(7) The context needs to contain a salient meaning denoting an element of ' $x$ B' (the FSV of C).

In what follows I will often loosely speak of the requirement for an antecedent of the form ' $x$ B', which should be understood as a shorthand for (7).

To exemplify, consider the correction sequence in (8) (material in parentheses is given for context only):

(8) a. (Jeanne recommend Mike for the job. - No,...)

b. ...she recommended PAUL for the job.

A possible representation for $(8 \mathrm{~b})$ is $(9)$ :

(9) [she recommended Paul F for the job]

The FSV of this sentence (the sister of $\sim$, to be precise) is 'she recommended $x$ for the job', a set of propositions (where $x$ ranges over individuals). requires that for (9) to be felicitous, some such proposition must be salient in the context. Since (8a) denotes just such a proposition, all is well in (8).

As a second illustration, consider (10):

(10) An AMERICAN farmer took a CANADIAN farmer out for a BEER.

The fact of interest here is that, as indicated by the capitalization, American/Canadian is focused, and consequently, farmer deaccented. Using the object for illustration, the domain of this focusing must be the NP Canadian farmer as in (11):

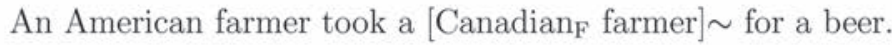


What's New (and What's Given) in the Theory of Focus?

The FSV of that NP is ' $x$ farmer', which matches the denotation of the subject NP, 'American farmer', as required by MATCH. Note that any larger focus domain, say took a Canadian farmer or took a Canadian $_{F}$ farmer for $a$ beer would not meet МAтCH, since 'took an $x$ farmer' and 'took an $x$ farmer for a beer' are not salient in the context.

A second fact to note about (10) is that while the accent 'shifts' from farmer onto Canadian due to focus, the main accent of the sentence is on beer, just like it would be if the object were a Canadian banker (i.e. no local focusing). This follows from the following F-to-Accent Mapping:

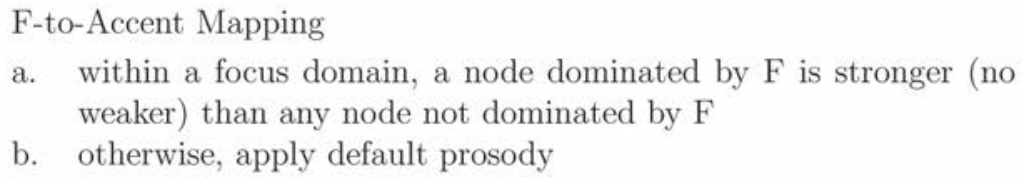

a. within a focus domain, a node dominated by $\mathrm{F}$ is stronger (no weaker) than any node not dominated by $\mathrm{F}$

b. otherwise, apply default prosody

Returning to the issue of where and when to form focus domains, consider now the following representations for $(8 \mathrm{~b})$ above:

(13) Jeanne recommended Mike for the job. - No...
a. [she recommended $\mathrm{PAUL}_{\mathrm{F}}$ for the job]
b. she $\left[\right.$ recommended $\left.P a u l_{F}\right] \sim$ for the job
c. she recommended Paul for the job

(13a) is the desired representation, discussed above. But the alternatives in (13b) and (13c) are wrongly predicted to be ok, too. 'Recommend Mike' is salient, and in the FSV of recommend Paul , 'recommend $x$ '; so (13b) meets MATCH. (13c) doesn't have any focus domain, and hence MATCH is not invoked, let alone violated, at all.

The problem is that both (13b) and (13c) would be pronounced with the main pitch accent on $j o b$, since that is where default prosody puts it, and in neither case is $j o b$ part of a focus domain which would 're-direct' the accent. But intuitively it is completely infelicitous to accent $j o b$ in this example.

What goes wrong here is that the focus domain in (13b) is too small; it should include for the job as well, in which case the correct accenting is derived. And similarly, (13c) should have a focus domain to begin with, and then one which includes the entire sentence (or at any rate Paul and job). 


\section{Daniel Büring}

One way to remedy this is to require that MATCH applies to every constituent in the clause. Put differently, every constituent is a focus domain. So while there would be nothing wrong with the domain in (13b), which, by (12) directs the accent onto Paul, there has to be another domain encompassing the entire sentence, and in that domain, too, the main accent has to be on Paul, thereby forcing deaccenting of job.

This, in effect, is the proposal in Schwarzschild (1999), which requires that every constituent be Given, in a technical sense used there. As pointed out earlier, MATCH in (4) has very similar effects to Schwarzschild's Givenness condition, and hence the requirement that every constituent be a focus domain (and hence invoke MATCH) closely follows Schwarzschild's proposal.

As noted in that paper, the proposal also closely follows earlier work on focus and accent in English, such as Rochemont (1986) and in particular Selkirk $(1984,1995)$, which, too impose certain requirements of being contextually salient on every constituent in the clause. We will introduce our own, slightly weaker version of this requirement in section 3 below.

\subsection{Overfocusing}

Consider another variant of our earlier example:

(Did Jeanne recommend Mike for the job? - No,...) [she recommended $\mathrm{PAUL}_{\mathrm{F}}$ for the $\left.\mathrm{JOB}_{\mathrm{F}}\right] \sim$

In (14), both Paul and job are focused. By (12), both are pitch accented, and by default prosody, the final pitch accent is stronger than the pre-final ones, yielding the main accent on job once more, contrary to the desired outcome.

The obvious problem is that $j o b$ is focused, but shouldn't be. But formally, MATCH is met in (14), because the FSV of the sentence, 'Jeanne recommended $x$ for $y$ ' does contain 'Jeanne recommended Mike for the job', which is a salient antecedent in (14). This is an instance of the problem known as OVERFOCUSING.

Schwarzschild (1999) provides a remedy against overfocusing as well, in the form of a constraint AvoIDF!, which basically says that among two competing F-patterns that both meet all other conditions on focus, the one with fewer F-markings is to be preferred. Thus, (9) is preferable to, and hence rules ungrammatical, (14). 
What's New (and What's Given) in the Theory of Focus?

The same route is open here: Within each focus domain, focus as little as possible while still meeting МAтcH. Our final proposal in section 3 will entail such a constraint.

\section{Maximize Anaphoricity, and a New Theory of Domain Formation}

One way to motivate Schwarzschild's AvoIDF! principle is in terms of what it does for the anaphoric relations a sentence enters into. Note that MATCH essentially imposes an anaphoric requirement on the context: That a certain meaning (out of the FSV) must be prominent.

To facilitate discussion, let me define the notion of Anaphoric Constituent:

Anaphoric Constituent (in a focus domain)

A constituent $\mathrm{C}$ within a focus domain $\mathrm{D}$ is anaphoric if it neither bears, nor is dominated by, an F-marker in D.

Thus in $\left[A_{F} B\right] \sim, \mathrm{B}$ is an Anaphoric Constituent; $\mathrm{A}$, and anything dominated by it, is not. Intuitively, an anaphoric constituent in a focus domain D is one whose meaning is constant in all the alternatives in the FSV of D.

Suppose now that there is a principle that says that it is good to have as many Anaphoric Constituents in a focus domain as possible (cf. 'Don't Overlook Anaphoric Possibilities' in Williams, 1997). ${ }^{2}$ Among other things, this principle would favor stingy use of F, since every F-marked constituent is no longer anaphoric itself, nor is any constituent that is dominated by it. Likewise, given the choice between a focus on a constituent $\mathrm{A}$ and a proper subconstituent $\mathrm{B}$ of $\mathrm{A}$, this principle favors focusing $\mathrm{B}$, since whatever is included in A but not B is then anaphoric.

(17) states such a principle, based on the generalization of (15) in (16):

(16) Anaphoric Constituent

A constituent $\mathrm{C}$ within a phrase marker $\mathrm{S}$ is anaphoric if it is anaphoric in a focus domain within $\mathrm{S}$.

(17) Maximize Anaphoricity (MaxAna):

Maximize the number of Anaphoric Constituents in a sentence, while

\footnotetext{
${ }^{2}$ Other predecessors include the Attentiveness Maxim in Schwarzschild (1997) and Maximize Presuppositions in Sauerland (2005).
} 


\section{Daniel Büring}

respecting МАTCH.

MaxAnA not only favors fewer F-marks and smaller foci, but also big focus domains, since anything not included in any focus domain cannot, by definition, be an Anaphoric Constituent. MAXANA will make the whole sentence a focus domain, unless the entire sentence would then need to be F-marked. Furthermore, it will make each F-marked constituent itself a focus domain (unless that domain, again, wouldn't contain any Anaphoric Constituents). Take (18) as a simple example again:

$$
\text { [she recommended }[\mathrm{Paul}]_{\mathrm{F}} \text { for the job] }
$$

(18) meets Match because Paul is F-marked, and 'she recommended $\mathrm{x}$ for the job' matches the previous utterance (she recommended Mike for the job). The root focus domain makes she, recommended, for the job, recommended Paul, recommended Paul for the job, and she recommended Paul for the job Anaphoric Constituents.

No further focus domains could possibly introduce any additional Anaphoric Constituents; the only candidate, obviously, would be Paul, that is, one could try something like (19):

$$
\overbrace{\substack{\mathrm{DP} \\ \text { Paul }}}^{\mathrm{DP}_{F}}
$$

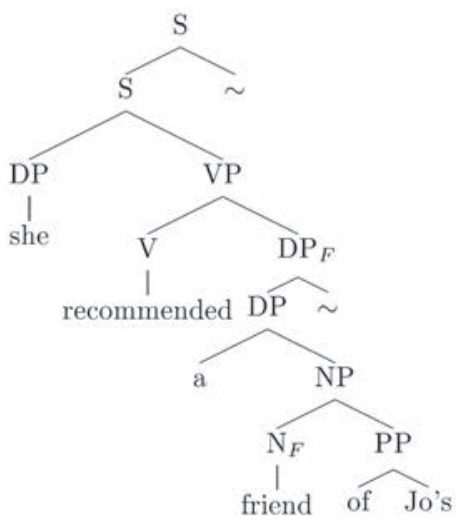

However, the focus domain [Paul] does not meet MATCH, since Paul is not salient in the context. To meet Match, Paul would need to be F-marked, but then the focus domain doesn't have any Anaphoric Constituent in it, and we may as well leave it out. 
What's New (and What's Given) in the Theory of Focus?

If we have a larger focus with another focus in it (deaccenting), e.g. (21), MAXANA will urge the construction of two focus domains, as in the tree in (20) above:

(21) (Who did Jo's mom recommend? -) She recommended a FRIEND of Jo's.

If a larger focus contains only new elements, it need not itself be a focus domain. The situation is essentially the same as with $\left.\int_{D P P a u l}\right]_{F}$ above. If on the other hand, a larger focus contains only new items, it will form a focus domain, but one without any F-markings. That way, all elements within the domain become Anaphoric Constituents, maximizing Anaphoric Constituents. $^{3}$

Note that in this set-up, all-new constituents and all-given constituents differ in focus domain assignment (all-given constituents must be (part of) focus domains, whereas all-new constituents needn't, since they don't increase the number of Anaphoric Constituents), but not F-marking (none in either). Consequently, both will show default prosody. I take this to be a positive results, since, as is well known, all-new and all-given constituents regularly display the same prosody. Under the present proposal, this is so by necessity since neither contains any F-marking. This feature will also become relevant in our discussion of Wagner's examples below.

\section{Wagner's (2006) Challenge}

In the discussion so far we have assumed, with Rooth (1992), Schwarzschild (1999), the rather weak MATCH condition on focus, and invoked no notion of contrast other than 'be in the FSV of'. We will now review some recent arguments presented in the literature that suggest that a stronger notion is required.

\footnotetext{
${ }^{3}$ I have not stated a principle that limits the formation of focus domains to those that increase anaphoricity. So in principle, one could still make any constituent a focus domain. One can prove, however, that no focus domains besides the two kinds just mentioned (root, and below any F-marker) will increase anaphoricity (basically any additional domain would be a proper subdomain of either the root domain or one of the sub-F domains, and therefore not introduce any new Anaphoric Constituents). All examples discussed here only include the minimal amount of focus domains necessary to maximize anaphoricity. One could add a constraint 'Avoid focus domain' to the system, but at present I see no harm in having optional additional focus domains.
} 
Daniel Büring

\subsection{Deaccenting requires local contrast}

Consider (22) from Wagner (2006):

(22) Mary's uncle, who produces high-end convertibles, is coming to her wedding. I wonder what he brought as a present.

a. He brought a [CHEAP convertible].

b. \#He brought a [RED convertible]

c. He brought a red convertible.

In the context of (22), (22a), with a deaccented noun, is an acceptable answer, as expected: cheap $_{F}$ convertible matches 'high-end convertible(s)'. By the same token, $(22 \mathrm{~b})$ would be expected to be fine, since red $_{F}$ convertible matches 'high-end convertible' just the same. But deaccenting here seems odd. The natural response (in the context of (22)) in this case is (22c).

I found similar judgements for a number of sentences I made up and informally asked about a dozen speakers to judge, using a questionnaire. In the following two examples, at least half of the speakers preferred deaccenting the noun and accenting the adjective alone:

(23) a. Mary plays many instruments, her favorite being the Spanish guitar. So I asked if she would play on my birthday. — She agreed to play some electric guitar.

b. Steve is a Steinway dealer (the finest pianos in the world). He's also my daughter's godfather. I wonder what she'll get from him for her 5th birthday. - He'll probably get her a cheap piano.

On the other hand, less than a third of the speakers accepted a deaccented noun in the following examples, and nearly everyone preferred a regular accent pattern with accent on both $\mathrm{A}$ and $\mathrm{N}$, the latter nuclear:

(24) a. Sarah is well known for her delicious chocolate cakes. So when we had a potluck dinner, guess what she signed up for bringing? - She signed up to bring a small cake.

b. Kate has this amazing record collection, which is the apple of her eye. But when she was strapped for cash, guess what she sold? — She sold some classical records.

The contrast between (24) and (23), in particular the lack of deaccenting in (24) raises the same question as Wagner's $(22 b) /(22 c)$ : Why is the noun, 
What's New (and What's Given) in the Theory of Focus?

whose meaning is clearly salient in these discourse, not made an Anaphoric Constituent, and hence deaccented?

\subsection{Wagner's Proposal}

Intuitively, what goes wrong in (22b) is that deaccenting the noun (inappropriately) suggests that 'red convertible' contrasts with 'high-end convertible'. 'Cheap convertible', on the other hand, does contrasts with 'high end convertible', so deaccenting the $\mathrm{N}$ in (22a) is felicitous. This is precisely what Wagner (2006) claims, proposing the constraint in (25):

(25) An expression and its alternative(s) must contrasts.

In other words, the set of alternatives to a focused expression is restricted to those meanings that semantically contrast with the meaning of the focused item (and are in the same denotation domain). Accordingly, 'high end' is an alternative to cheap, but not to red.

Wagner's particular implementation differs from the type of system discussed in the present paper in various other ways, most notably in that grammar marks $\mathrm{G}$ (ivenness), rather than $\mathrm{F}$ (ocus). The central condition on the interpretation of G-marking is paraphrased in (26):

(26) A structure of the form $\left[A B_{G}\right]$ is well-formed only if there is a (contrasting) alternative $\mathrm{A}^{*}$ to $\mathrm{A}$ s.t. ' $\mathrm{A} * \mathrm{~B}$ ' is salient.

In the case of (22a), the representation that yields deaccenting of the $\mathrm{N}$ is CHEAP convertible ${ }_{G}$, i.e. $\mathrm{A}=$ cheap, $\mathrm{B}=$ convertible; since the context contains (and thus makes salient) the phrase high-end convertible, and since 'high-end' is an alternative to 'cheap', we can have $\mathrm{A}^{*}=$ high-end, meeting (26).

To justify $\mathrm{N}$-deaccenting in (22b), we'd need a representation $R E D$ convertible ${ }_{G}$, which in turn requires that ' $A$ * convertible' be Given, where $A *$ is an alternative to 'red'. The only likely antecedent is high-end convertible, which would require that $\mathrm{A}^{*}=$ 'high end', but since 'high end' is not an alternative to 'red', this option, and thus deaccenting $\mathrm{N}$, is impossible. ${ }^{4}$

\footnotetext{
${ }^{4}$ Wagner doesn't provide a representation for the felicitous version (22c), but presumably this would have to be one of the representations in (i):
}

a. he brought her a red convertible 


\section{Daniel Büring}

It should be noted that the choice of G-marking over F-marking does not seem essential here. Assume we added (25), the requirement that focus alternatives be 'truly contrastive' with the focused item, to the theory from section 3 . The prerequisite representation to deaccent $\mathrm{N}$ would be (27):

$$
\text { (he brought) }\left[\mathrm{DP} \text { a }\left\{\begin{array}{l}
\operatorname{red}_{\mathrm{F}} \\
\operatorname{cheap}_{\mathrm{F}}
\end{array}\right\} \text { convertible }\right] \sim
$$

The obvious antecedent is 'high-end convertible', and in order to meet MATCH - that the antecedent be in $\llbracket \mathrm{DP} \rrbracket_{\mathcal{F}}$ - 'high end' must be an element of $\llbracket A_{F} \rrbracket_{F}$, which it is for $A=$ cheap, but not for $A=$ red. Thus in the latter case the correct structure would have to be $(28):^{5}$

$$
\text { [ he brought } \left.[\text { a red convertible }]_{\mathrm{F}}\right] \sim
$$

This would be ok, since the set of alternatives ('he brought candy', 'he brought a harp', 'he brought a red convertible', 'he brought a red convertible',...) is matched by the question (I wonder) what he brought as a present.

Wagner (2006) similarly notes that his proposal could be implemented in the system of Rooth (1992), using F-marking. But recall that that system doesn't specify conditions on when to form focus domains. And indeed it is crucial for the F-version that not every constituent needs to be a focus domain. For consider what would happen if red and convertible n (28) had to be focus domains on their own. If neither is F-marked, their FSVs are \{'red'\} and \{'convertible' $\}$ respectively, so they need to find salient antecedents 'red' and 'convertible'. This is easy for the latter, but not for the former, since 'red' is not salient in the context. F-marking red, however, will not help either, assuming that the set of its focus alternatives does not contain 'high-end' (as per the 'true alternative' requirement). In other words, red neither has a salient antecedent, nor is it contrastive, and hence there is no appropriate marking for it in isolation (note that red convertible in turn is contrastive, since it contrasts with other possible things the uncle could have brought). This is why this type of example is problematic for a theory like Schwarzschild (1999), in which every constituent must be Given ( $\approx$ meet МАтсH).

b. [he brought her $]_{\mathrm{G}}$ a red convertible

\footnotetext{
${ }^{5}$ Here, too, a structure without any F-marking would do the trick as well, though I suspect that this is just a coincidence.
} 
What's New (and What's Given) in the Theory of Focus?

Wagner's proposal elegantly circumvents this problem by putting the contrast requirement on the complement of the G-marked node. Therefore, not every non-G-marked constituent must be contrastive, but only the 'biggest' one, which in (28) is a red convertible.

Following the proposal from section 3 above, not every constituent needs to be a focus domain. But does it allow the structure in (28)? Not quite. We should in fact build a focus domain around convertible, which isn't in any focus domain yet, but could be made an Anaphoric Constituent:

[ he brought $\left.[\text { a red }[\text { convertible }] \sim]_{\mathrm{F}}\right] \sim$

It should also be clear that making red a focus domain wouldn't increase Anaphoric Constituents, since red is not anaphoric to begin with. What about the NP a red convertible, then? Without F-marking on red, this domain would violate MATCH, since 'red' is not salient. With F-marking on red, this doesn't introduce any additional ADs. But more importantly, since 'high end' is not a true alternative to 'red', red $_{F}$ convertible as a focus domain couldn't be matched with 'high-end convertible' (or any other salient meaning) to begin with, so this focus domain could never comply with MATCH. Since MaxAna only requires us to maximize Anaphoric Constituents to the extent that МАтCH is met, no further focus domains containing red are required by that theory.

\subsection{Explicating Contrast (at Least a Little Bit)}

Before going on I would like to elaborate a little on the notion of contrast alluded to in 'true alternative'. In Wagner's formalism, whether or not something is a true alternative is decided at the level of the focused element itself; 'high end' is an element of $\llbracket c h e a p_{F} \rrbracket_{\mathcal{F}}$, but not of $\llbracket \operatorname{red}_{F} \rrbracket_{\mathcal{F}}$. But the informal discussion in that paper already makes it clear that we should rather think of this in the context of other expressions. ${ }^{6}$ I will assume that whether or not an element of the FSV counts as a true alternative is decided at the level of the focus domain.

A second elaboration regards the notion of 'contrastive' itself. The intuition I'd like to formalize here, and again one that can be found in one way or the other in many places in the literature, is that cheap convertible and high

\footnotetext{
${ }^{6}$ Wagner's examples is: 'used' is a true alternative to 'new' in the context of 'car', but not 'boy friend'.
} 


\section{Daniel Büring}

end convertible contrast because it is immediately plausible to understand them as exclusive: 'a cheap, not a high end, convertible'. On the other hand, it is much less plausible to understand red convertible as 'red, not high end' - unless the context makes it clear that red convertibles are generally not high-end, in which case $R E D$ convertible is in fact perfectly possible. For now, I will frame this using the notion of an Issue.

For example, in (8b), the literal meaning of the focus domain is 'she recommended Paul for the job', and the contextually salient alternative from the FSV is 'she recommended Mike for the job'. The issue is: Did she recommend Paul for the job, or did she recommend Mike for the job?', or more abstractly: 'ordinary meaning or focus alternative(s)?' One condition on an issue must be that exactly one of the alternatives is true. Put differently, an issue is plausible if it is plausible to assume that every world in the context set belongs to exactly one of the alternatives in the issue. (8b) is felicitous because it is plausible that she either recommended Mike (but not Paul), or Paul (but not Mike).

In the case of the convertible, things are more complicated, since the focus domain is the NP, which denotes a property. The sentence thus asserts that he gave her a red convertible, and the issue addressed is whether that convertible is a red convertible or a high-end convertible. But this issue is an issue only if we can assume that the convertible he gave her is either red (but not high-end), or high-end (but not red). The reason this is odd is because it seems unmotivated to think that that should be true: the convertible could very well be red and high-end, or in fact neither. On the other hand, that it is either high-end (but not cheap), or cheap (but not high-end) seems to be a reasonable assumption (and hence the question, which one it is, an issue) in just that sense.

To a very rough approximation, we can state the pertinent focus condition as in (30):

(30) let A be a constituent of any type, and $\vec{x}$ a sequence of variables s.t. $\llbracket \mathrm{A} \rrbracket_{\mathcal{O}}(\vec{x})$ is a proposition, then $A \sim$ denotes $\lambda \vec{x}$. $\llbracket \mathrm{A} \rrbracket_{\mathcal{O}}(\vec{x})$, provided that...

a. there is a salient meaning $a$ which is in $\llbracket \mathrm{A} \rrbracket_{\mathcal{F}}$, (presupposition 1)

b. and whether $\llbracket \mathrm{A} \rrbracket_{\mathcal{O}}(\vec{x})$ or $a(\vec{x})$ is an issue (presupposition 2)

This should suffice to explicate the notion of contrast for the purpose of this 
What's New (and What's Given) in the Theory of Focus?

paper, though clearly much more needs to be said. ${ }^{7}$

\subsection{Interim Summary}

We've seen in this section that Wagner's examples make a case for focus being contrastive (in its domain). This is incompatible with the theory in Schwarzschild (1999), in which anything that is not Given is F-marked; rather, things can be new, yet non-contrastive. If, on the other hand, new things don't always need to be F-marked, we can't maintain that F-less elements in general don't need to be accented. This, presumably, is the reason Wagner proposes to mark G(ivenness), rather than F(ocus): Now everything that's not Given, contrastive or just new, is grouped together, to be marked by default stress and prosody.

We have seen, however, that the exact same empirical picture can be modelled using F-marking, rather than G-marking, within the system laid out in section 3 above; default prosody kicks in whenever there is no contrast in F-marking: within a focus, and outside of focus domains. There is thus no inherent reason to use $\mathrm{G}$ (as Wagner does), rather than F.

The natural question, then, is whether there are independent reasons to choose $\mathrm{G}$ marking over F marking, or vice versa. I believe that examples brought up in Kehler (2005) might provide such reasons.

\section{Kehler's (2005) Challenge}

\subsection{Data}

Kehler (2005) discusses the contrast between (31) (from Schwarzschild, 1999) and (32):

(31) John cited Mary, but...

\footnotetext{
${ }^{7}$ For example: If a focus domain $A$ doesn't contain any focus, $[A]_{\mathcal{O}}=\left\{[A]_{\mathcal{F}}\right\}$. The issue then must be 'A or A?' I suppose technically this may still be ok. Since A is not focused, we take it as a given that $\mathrm{A}$, and hence it is plausible to assume that in each context world, exactly one element of $\{\mathrm{A}\}$ is true.

Alternatively, we could go with intuitions and deem 'A or A?' a non-issue. In that case, there can't be any focus domains without foci, contrary to what I suggested in section 3 above. As far as I can tell, this will change some of the representations, but not the accenting they predict. I'll thus leave this issue open.
} 


\section{Daniel Büring}
a. ... he DISSED SUE.
b. ?... he dissed SUE.

Fred read the menu and then...

a. $\ldots$ he ordered a HAMburger.

b. \#... he ORdered a HAMburger.

There is at least a preference to accent both V and the object Sue in (31), but comparable double accenting seems distinctly odd in (32). Kehler presents these data as a challenge to the proposal in Schwarzschild (1999); while we cannot go into the details here, the challenge is roughly that according to that paper, every non-Given element needs to be F-marked, in particular both dissed and Sue (ordered and hamburger). But then how can the difference between the double-peak pattern and the single peak pattern be represented and interpreted? ${ }^{8}$

Kehler describes the difference between, say, (32a) and (32b) as that between one accent and two accents. I think more accurately, the difference is between one or two nuclear accents. The verb can be accented in either version, but when it does, its accent in (32a) (and (31b)) is less prominent than that on the object in these sentences, whereas in (31a) (and (32b)), V and $\mathrm{O}$ are accented equally strong. I submit that in (31a), $\mathrm{V}$ and $\mathrm{O}$ bear nuclear pitch accents, each within its own intermediate phrase. In (32a), there is only one intermediate phrase, and its nuclear accent is on $\mathrm{O} ; \mathrm{V}$ in this case can, but need not, bear a prenuclear phrase accent.

Pretheoretically, what we're dealing with here is the difference between one focus, (32b), and two foci, (31b). It is this intuition that I want to pursue.

\footnotetext{
${ }^{8}$ One would suspect that the difference is simply represented as follows: double accent $=($ ia) single accent $=($ ib) or (b'):

$$
\begin{array}{lll}
\text { a. } & {\left[\mathrm{V}_{\mathrm{F}} \mathrm{O}_{\mathrm{F}}\right]} & \text { b.' }\left[\mathrm{V}_{\mathrm{F}} \mathrm{O}_{\mathrm{F}}\right]_{\mathrm{F}} \\
\text { b. } & {[\mathrm{V} \mathrm{O}]_{\mathrm{F}}} &
\end{array}
$$

However, (ib) would require both $\mathrm{V}$ and $\mathrm{O}$ to be given, which they aren't in either example. On the other hand, it is unclear what would ever license (ib'), given that (ia) has the same givenness requirements (namely: none), and uses one less F-mark; so according to Schwarzschild's AvoIDF! principle, (ia) should block (ib').
} 
What's New (and What's Given) in the Theory of Focus?

\subsection{Proposal}

I want to suggest that in the double-peak examples, we express two separate contrasts, or issues. For example, John DISSED SUE, in the context given, contrast dissing Sue both with quoting Sue and dissing Mary; the issues are 'did he diss Sue or did he quote Sue?'; and 'did he diss Sue or did he diss Mary?'

On the other hand, the double peak in John ORDered a HAMburger, in the context given, would contrast ordering a hamburger with reading a hamburger and ordering the menu. The odd issues are 'did he order a hamburger or did he read a hamburger?'; and 'did he order a hamburger, or did he order the menu?'

I will assume that the domain for both foci is the entire clause, though as far as I can see, it could also be VP. What is crucial, however, is that each focus introduces an alternative relative to the ordinary meaning of its sister, even though that sister is itself focused. That is, we need one alternative of the form 'John $R$ Sue' (here: $R=$ 'quote') and one of the form 'John dissed $x$ ' (here: $x=$ Mary). One the other hand, neither of these alternatives is actually salient, though their combination, 'John quoted Mary', is.

This requires a complication in our focus semantics. We need to be able to selectively access foci in a domain. To do so, we follow Krifka (1991/2) and Wold (1996) in indexing foci. For an example like (33), we now have three FSVs (in the sentential domain):

John DISSED $\mathrm{F} 1_{1} \mathrm{SUE}_{\mathrm{F} 2}$.
a. John $R$ Sue
b. John dissed $x$
c. John $R x$

(33a) is the FSV for focus 1, (33b) the FSV for focus 2, (33c) the FSV simpliciter. In order to access these FSV, we index our domain operator $\sim$, yielding the full representation in (34):

$$
\text { (John quoted Mary, but) [[[he dissed } \left.\left.\text { Fi } \text { Sue }_{\mathrm{F} 2}\right] \sim_{1}\right] \sim_{2}
$$

$\sim_{1}$ retrieves the FSV for focus 1, (33a), and contrasts one of its elements (here: 'John quoted Sue') with 'John dissed Sue'. $\sim_{2}$ retrieves the FSV for focus 2, (33b), and contrasts one of its elements (that John dissed Mary) with 'John dissed Sue'. In addition, both $\sim_{1}$ and $\sim_{2}$ retrieve the FSV simpliciter, 


\section{Daniel Büring}

(33c), and require that one of its elements ('John quoted Mary') be salient in the context.

So we've seen that multiple free foci can be captured by our system, appropriately amended to allow for selective indexing of foci. Let me close by pointing out why this may argue in favor of marking $\mathrm{F}$, rather than G, as in W's system. Suppose we assumed the following condition (essentially Wagner's):

$\left[A B_{G}\right]$ is felicitous only if there is some $A^{*}$ s.t. $\left[A^{*} B\right]$ has an antecedent in the discourse.

Let us furthermore assume that a contrast condition just like the one contemplated here is imposed on $\left[\mathrm{A}^{*} \mathrm{~B}\right]$, and finally, and this is crucial, that ' $\mathrm{A}$ ' in (35) is understood to mean 'A with or without G' (this is certainly not W's intention, but it seems the best shot we have at making G-marking do what F-marking does so far). In that case, we could aim to represent (31a) as in (36), which would effectively count as two instances of (35), namely (36a) and (36b), with the conditions given below them:

(36) he dissed Sue $_{\mathrm{G}}$

a. he $\operatorname{dissed}_{\mathrm{G}}$ Sue

it is given that he $X$-ed Sue

b. he dissed Sue $_{\mathrm{G}}$

it is given that he dissed $y$

The problem with this is that neither 'he $X$-ed Sue' nor 'he dissed $y$ ' are in fact given. Could we amend the system further, along the lines of (37)?

$\left[A B_{G}\right]$ is felicitous only if for some $A^{*}$, 'AB or $A^{*} B^{\prime}$ is an issue.

Assuming (36) and (37), we could get to the issues 'did he diss Sue or Mary' and 'he diss or quote Sue'. This seems right. But note that now there is no actual requirement of saliency on A or B any more. In Kehler's cases, this is fine, but in these cases, B itself is accented. In the general case, however, B is unaccented, and this should only be possible if its meaning is salient.

A further problem lies, I suspect, in the syntax-to-prosody mapping. Note that in (36), both G-marked constituents must be accented. This should happen if and only if one G-marked constituent is sister to another G-marked constituent (in all other cases, G-marking should correspond to deaccenting). 


\section{What's New (and What's Given) in the Theory of Focus?}

Though accenting G-marked material may strike one as counter-intuitive, this could still be captured by a syntax-to-prosody mapping along the lines of (38):

(38) a. if in $\left[\begin{array}{ll}A B & B\end{array}\right]$ (order irrelevant), $\mathrm{A}$ is G-marked and $\mathrm{B}$ is not, $\mathrm{B}$ is metrically stronger than $\mathrm{A}$; otherwise...

b. apply default prosody

But note that in the double-accent examples such as He DISSED SUE, the accent on dissed is actually stronger than in the default case (I argued above that it is a nuclear accent within an intermediate phrase he dissed). It is unclear how this effect would follow from G-marking.

Does it follow from F-marking? We required that a focus within a focus domain is no weaker than any other element in that domain. A straightforward way to use this is to say that two nuclear accents, i.e. two intermediate phrase heads, are equally strong, whereas for each two accents within an intermediate phrase, one is stronger. It follows that whenever a domain D contains more than one focus - either because D has two foci, or because D overlaps with another domain whose focus falls into D (and is different from the focus of D), two intermediate phrases must be formed. ${ }^{9}$

\section{Summary}

In this paper I addressed three issues: The nature of the pragmatic condition on focusing (MATCH or CONTRAST), how to get enough focus domains so as to predict accent patterns (every node is a focus domain, or Maximize Anaphoricity), and how to represent focus in the syntax (F-marking or Gmarking).

It was shown that, if we accept the arguments in Wagner (2006) to the effect that МАTCH is an insufficiently weak condition on focusing, we are lead towards a system that maximizes focus domains, but doesn't require every node to be one. We are not forced, however, to use G-marking rather than

\footnotetext{
${ }^{9} \mathrm{~A}$ slightly more involved theory would go as follows: (A) For any domain, the focus has to be strongest in the prosodic constituent containing that domain. Clearly, if a domain contains two foci, A will be violated. Crucially, violations of A are cumulative: one violation for every element of the focus domain which is not within the prosodic constituent in which $\mathrm{F}$ is maximally prominent. In other words, each focus will try to be maximally prominent in as big a sub-part of its domain as possible.
} 
Daniel Büring

F-marking; the two options seem to fare equally well. Finally I argued that in order to extent the analysis to cases of double focusing, or juxtaposition, it may be preferable to indeed mark focus, not its complement, givenness.

Based on a new notion of Anaphoric Constituent, I proposed a new, formal implementation of what it means to maximize focus domains, MAXANA. I argued that this condition also subsumes the effects of the constraint AvoIDF in Schwarzschild (1999) I proposed an implementation of the notion of anaphoricity which is, to the best of my knowledge, novel. Finally I sketched a first formal implementation of the notion of contrast used here.

\section{References}

Jacobs, Joachim, 1991/2. Informationsstruktur und Grammatik. Opladen: Westdeutscher Verlag. (= Linguistische Berichte Sonderheft 4).

Kehler, Andrew, 2005. Coherence-Driven Constraints on the Placement of Accent. In Proceedings of the 15th Conference on Semantics and Linguistic Theory (SALT-15).

Krifka, Manfred, 1991/2. A Compositional Semantics for Multiple Focus Constructions. In Jacobs (1991/2), 17-53.

Rochemont, Michael, 1986. Focus in Generative Grammar. Amsterdam/Philadelphia: John Benjamins.

Rooth, Mats, 1992. A Theory of Focus Interpretation. Natural Language Semantics 1:75-116.

Sauerland, Uli, 2005. Don't interpret focus: Why a presuppositional account of focus fails, and how a presuppositional account of givenness works. In Proceedings of Sinn und Bedeutung 9, 370-384. Nijmegen.

Schwarzschild, Roger, 1997. Interpreting Accents. Ms. Rutgers University .

Schwarzschild, Roger, 1999. GIVENness, AvoidF and Other Constraints on the Placement of Accent. Natural Language Semantics 7(2):141-177.

Selkirk, Elisabeth, 1984. Phonology and Syntax: The Relation between Sound and Structure. Cambridge, Mass.: MIT Press. 
What's New (and What's Given) in the Theory of Focus?

Selkirk, Elisabeth, 1995. Sentence Prosody: Intonation, Stress, and Phrasing. In John A. Goldsmith, ed., The Handbook of Phonological Theory, 550-569. London: Blackwell.

Wagner, Michael, 2006. Givenness and Locality. In Jonathan Howell and Masayuki Gibson, eds., Proceedings of SALT 16. Ithaca: CLC Publications.

Williams, Edwin, 1997. Blocking and Anaphora. Linguistics Inquiry 28:577628.

Wold, Dag, 1996. Long distance selective binding. the case of focus. In Teresa Galloway and Justin Spence, eds., Proceedings of Semantics and Linguistic Theory (SALT) VI, 311-328. Ithaca, NY: Cornell University.

Daniel Büring

Linguistics Department

University of California Los Angeles

Campbell Hall

Los Angeles, CA 90095-1543

buring@humnet.ucla.edu 